\title{
DOUBLE ORBITAL SARCOMA
}

BV

MAJOR H. KIRKPATRICK, I.M.S.

SUPERINTENDENT OF THE GOVERNMENT OPHTHALMIC HOSPITAL, MADRAS, INDIA.

DOUBLE symmetrical sarcoma of the orbit must be sufficiently rare to make the occurrence of a case worth recording.

The case referred to occurred in a male Mohammedan Indian, aged 50 years, who was admitted to the Madras Ophthalmic Hospital on the 21st of July, 1916.

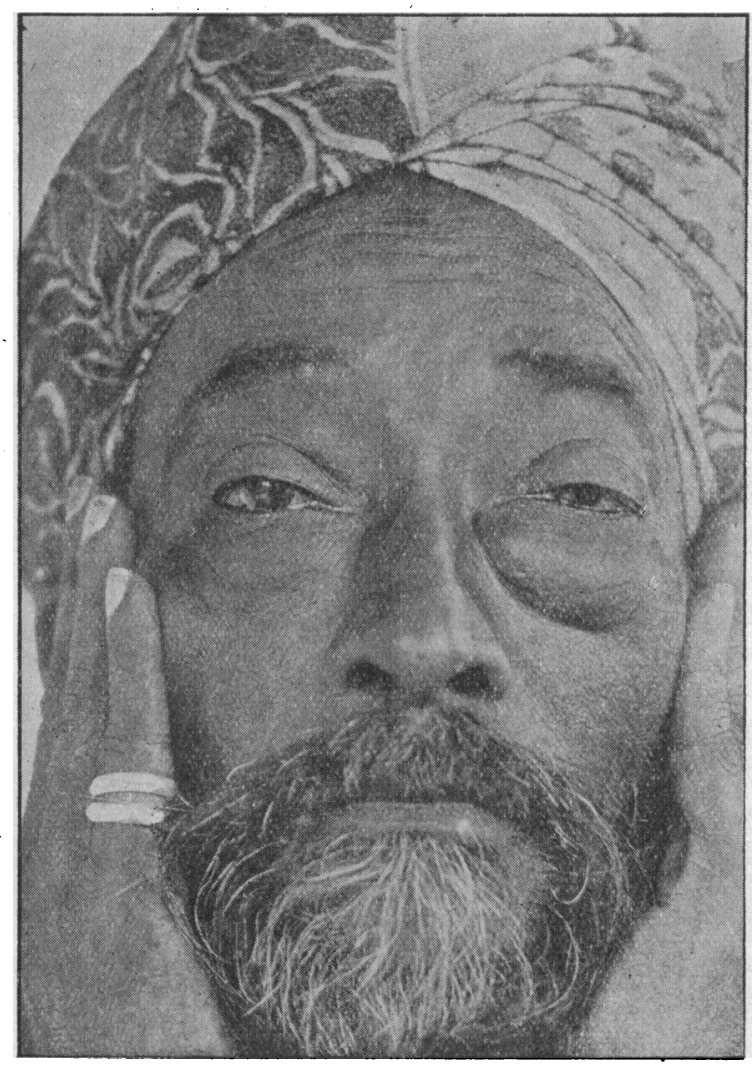

FIG. 1.

He stated that the trouble began in the right eye a yearlpreviously, when he noticed water, and later, pus collecting at the inner angle of the eye. Two months before admission, he observed a tumour in the lower lid of that eye. Watering of the left eye began six months before admission, and the tumour was noticed in 
the lower lid one month later. This began in the lacrymal sac region and gradually spread outwards. No pain was ever present on either side. His general health had always been good, but he had suffered from excessive sneezing since the watering of the eyes began.

Both the lower lids were prominent and pouched, and a firm, welldefined tumour, which reached far back into the orbit, could be felt beneath each of them. The tumour on the left side was slightly bigger than that on the right (Fig. 1). But the difference between

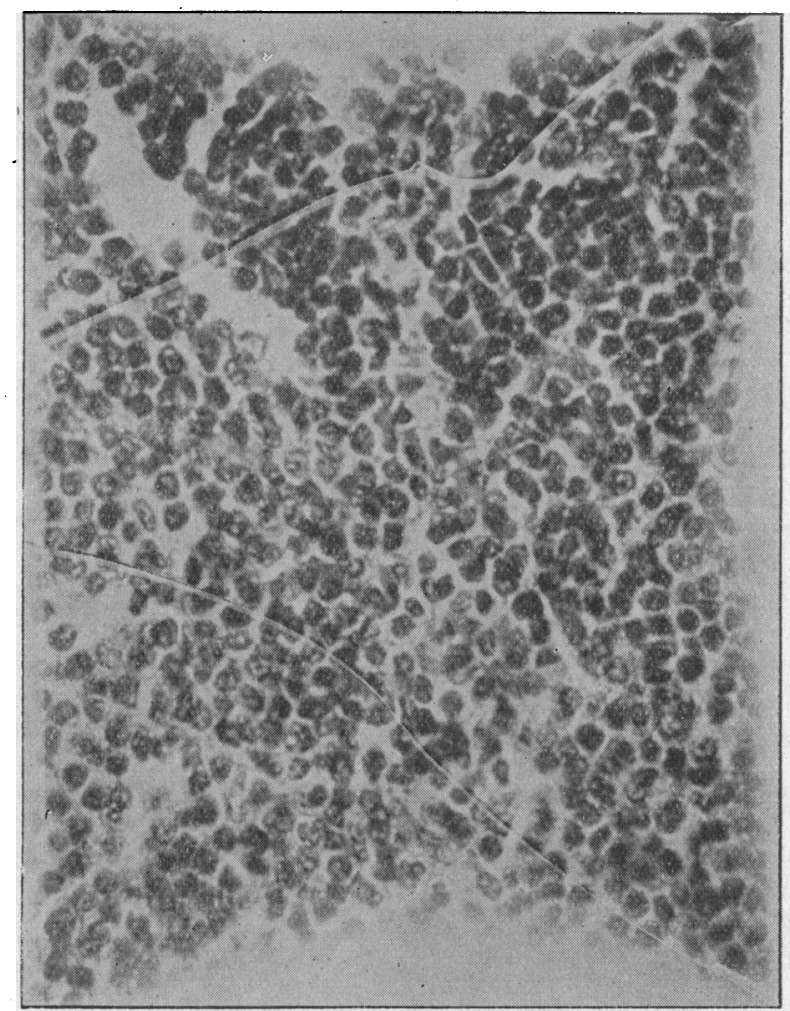

FIG. 2.

the two sides is somewhat exaggerated in the figure. The skin and orbicularis muscles were freely moveable over the tumours. Movement of the eyeballs downwards was limited. Purulent retention was present on the right side, whilst on the left the lacrymal passages were obstructed but free from retention. No glandular enlargement was present.

The tumours were removed on July 22nd, 1916. That on the left consisted of two lobules which were semi-transparent, with 
bluish and pink mottlings, and were united by a firm fibrous band. It stretched far back into the orbit and was fixed to the inner wall and to the tissues behind. The right tumour was smaller and more elongated. It was lobulated but single. One very firm attachment lay over the lower end of the lacrymal sac, and it was also firmly fixed to the orbital tissues.

On microscopical examination (Figs. 2 and 3), the tumours were found to be identical in structure. They were composed of cell

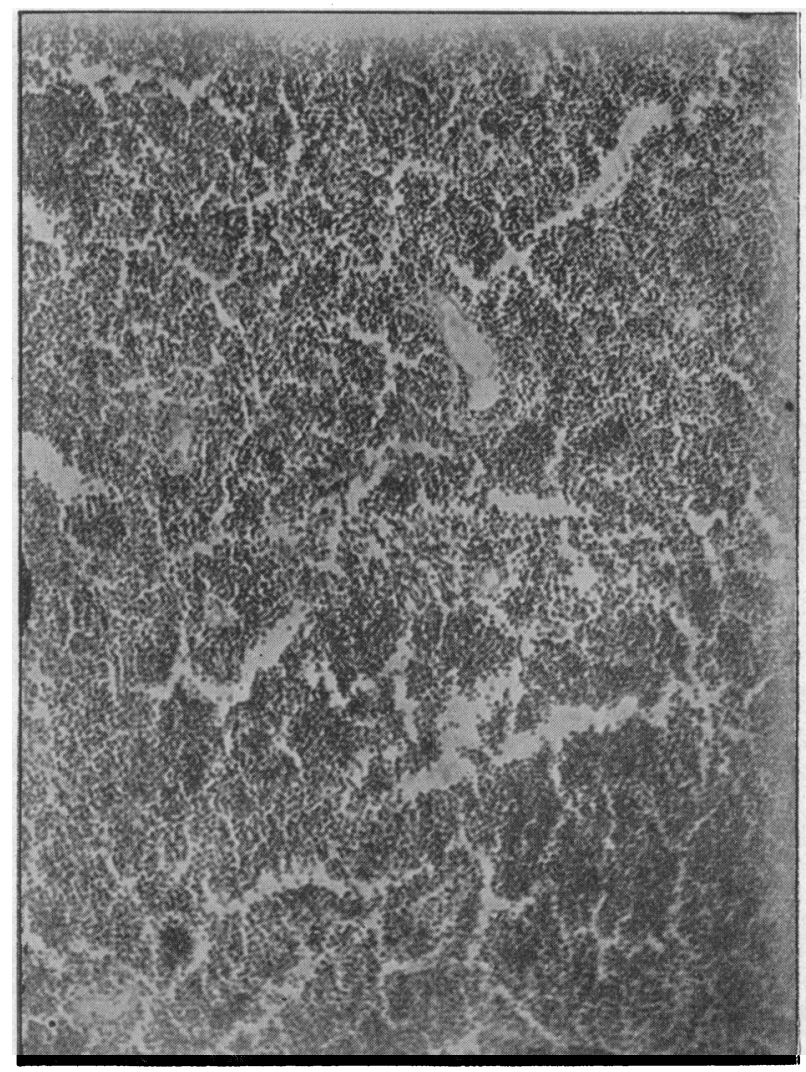

FIG. 3.

groups separated by fine branching spaces giving a streaky appearance to the section. Many of the spaces contained red blood corpuscles. The cells were rounded and oval, with very little protoplasm in proportion to the nucleus. Some of the nuclei had a vesicular appearance. The tumour was probably an endothelioma of sarcomatous type.

The patient made a very good recovery, but the action of the ocular muscles was interfered with for about a month. He was 
last seen three months after the operation, at which time he was very comfortable and no recurrence had taken place.

I have to thank Sub-Assistant Surgeon Rangonath Rao for the photograph of the patient.

The micro-photographs were taken from the tumour removed from the right side.

\title{
THE HUNTERIAN LECTURES ON THE INDIAN OPERATION OF COUCHING FOR CATARACT
}

\author{
Delivered at the Royal College of Surgeons of England on \\ February 19th and 21st, 1917
}

\section{A Summary}

BY

Lieut.-Col. Robert HeNr Ey Eliot, I.M.S. (retd.) LONDON.

THE operation of couching for cataract was practised and described by Celsus at the very beginning of the Christian era, and many contributions to the literature of the subject have since been made. It is probable that it was introduced into Europe from the East, and it was certainly known and practised in the Orient for many hundreds of years before its first whisper in the annals of Western surgery. From the time of the advent of the British surgeon to India, couching attracted much notice, but it was not until the work of Lister began to bear fruit that the crude and filthy methods of the coucher excited a due amount of horrof in the minds of the exponents of modern surgery. The lecturer has studied the methods of these men for over twenty years, and has collected and carefully compiled records of 780 cases of couching ; in addition, he has been able to obtain 54 globes on which the operation had been performed. This latter collection he has now presented to the Museum of the Royal College of Surgeons of England.

There are two distinct operations performed, viz., the anterior, in which the lens is attacked through the cornea or limbus from the front, and the posterior, in which the incision is placed behind the ciliary body, well back in the sclera. The latter is by far the more scientific procedure, two instruments being used, and a deliberate attempt being made to break down the suspensory ligament of the lens before its dislocation is attempted. Owing to the dirty methods of its exponents, and to the crude instruments used, the results of couching are very bad indeed, only $21^{\circ} 64$ per cent. of operations yielding a visual result equivalent to $1 / 10$ or better. It 